\title{
THE ROLE OF THE PROPRIETARY HOSPITAL
}

\author{
Bruce Steinwald* and Duncan Neuhauser $\dagger$
}

\section{INTRODUCTION}

Within the hospital industry ${ }^{1}$ in the United States there are few issues more controversial than that concerning the role of proprietary hospitals and the consequences of their operation. ${ }^{2}$ This controversy is striking in view of the fact that in Ig68 only r3.2 per cent of all nonfederal, short-term general and other special hospitals were proprietary, accounting for only six per cent of the total beds. ${ }^{3}$ Furthermore, the proportion of proprietary hospitals and beds has been declining over time, and yet the debate over proprietary hospitals has grown in recent years.

What accounts for this apparent increase in interest? No doubt it is due in part to a general increase in interest in the hospital industry as a whole. Mounting dissatisfaction with the voluntary, nonprofit mode of hospital operation has grown as hospital costs have increased relative to other prices. It has been argued that the virtue of profit-seeking hospitals is their greater incentive to control costs. Others argue that cost control, or lower costs, comes at the expense of quality of care or by selective admission of simple cases. Associated with this debate has been the recent spectacular performance in the stock prices of the recently formed proprietary hospital corporations which own a chain of hospitals. ${ }^{4}$

But whatever the source of interest in proprietary hospitals, the literature on them is woefully incomplete. The debate has been unencumbered by evidence that could conceivably resolve the difference in views, and the discussion has been polem-

- Research Associate, Center for Health Administration Studies, University of Chicago.

† Assistant Professor of Health Services Administration, School of Public Health, Harvard University.

We are indebted to Professor Reuben Kessel and Dr. Donald Goldstone for their comments. The research for this paper was financed by USPHS Grant HS o0080.

1 The ensuing discussion is limited to short-term hospitals (at least $50 \%$ of patients stay 30 days or less) unless otherwise stated, excluding federal, psychiatric, and tuberculosis hospitals. This subject matter corresponds to the American Hospital Association's (AHA) classification "Nonfederal, short-term general and other special" hospitals. It is primarily within this sphere that the current controversy over proprietaries exists.

${ }^{2}$ Proprietary hospitals are those which are owned and operated for a profit by individuals, partnerships, or corporations. Other major forms of ownership are voluntary nonprofit (under church or community sponsorship) and governmental (owned and operated at some level of government). The words proprietary and for-profit will be used interchangeably in this paper as they are in hospital literature.

${ }^{3}$ Hospitals (Guide Issue), Aug. I, x969, pt. 2, at 475.

- For discussions of these chains see American Hospital Association, Study of For-Profit Hospital Chains (mimeo. May 22, I970); Proprietary Hospitals Go Public, MoDERN Hospitar, Mar. 1969, at 80; Big, Bigger, Biggest-For-Profit Hospitals Chains Expand, Modern Hosprtal, Aug. I969, at 99; These Are Claims for Hospital Corporations: Capital, Talent, Size, Centralization, Modern Hosprtal, Dec. I969, at 102; More Companies Enter Hospital Field: Alarm Non-Profit Institutions, Wall Street Journal, Oct. 13, I969, at I; Thurlow, Hospital Chains: The Proprietary Comeback, MEd. Econ., June 9, 1969, at 122; Wasyluka, New Blood for Tired Hosptals, Harv. Bus. Rev., Sept.-Oct. 1970, at 65. 
ical. This paper represents an attempt to evaluate what evidence exists that bears on the issues immediately presented in this debate. It is divided into three parts. First, there is a brief statistical and descriptive history of proprietary hospitals. The second part is a quantitative description of proprietary hospitals as they exist today, with some emphasis placed on current trends and on influences on the share of the hospital market held by proprietaries. An attempt is made to build a statistical "model" that will, in part, explain the role of the proprietary sector of the hospital industry. Third, there is a summary of the main issues that surround proprietary hospitals. This is an attempt to extract from the literature the main arguments, pro and con, that seem to center on basic points of contention regarding proprietary hospitals.

\section{I}

\section{HISTORY}

In I873 the U.S. Bureau of Education reported 178 hospitals of all types in the United States. ${ }^{5}$ By 1909 , according to the American Medical Association, there were 4359 hospitals in the United States. ${ }^{B}$ During this period antiseptic and aseptic surgery and radiology made the hospital for the first time indispensable to physicians caring for both poor and well-to-do patients. This rapid growth of hospitals and their use by paying patients resulted in a rapid growth in proprietary hospitals. According to the National Hospital Record in Ig04,

Those who have kept in close contact with hospital growth in the United States have not failed to note the rapid increase in hospitals established and owned by individual physicians (e.g.) during its first year, the Morrison Hospital was a little more than self sustaining, and thus far in its second year it is providing a very satisfactory investment. ${ }^{7}$

During the late I8gos, the National Hospital Record reported the sale of dozens of proprietary hospitals from one owner to another, suggesting that there was a market for such hospitals.

We know of no record of the number of proprietary hospitals before the AMA started collecting such figures in I927. However, a very rough estimate may be possible. The Bureau of the Census, in its Benevolent Institutions 19ro, lists rg18 hospitals, excluding hospitals "conducted on a distinctly business basis." For Igog the AMA reported 4359 hospitals including proprietary hospitals. If we can assume

\footnotetext{
TThe U.S. Bureau of Education study is discussed in M. Lerner \& O. Anderson, Henlth Procress IN THE UNited STATEs, I900-I960, at 236 (1963). Approximately $40 \%$ of these hospitals were for the insane.

${ }^{6}$ I27 J.A.M.A. 772, 776 (1945). The AMA made these surveys through 1945. The results of these surveys are reflected in Table $x$ infra, covering I909-4I (all hospitals) and 1938-4I (proprietary hospitals).

78 National Hospital Record (I904). The data in Table 1 infra for total hospitals in 1878 and I903 can be found in 7 National Hospital Recond (I903). The Ig03 figure is admitted to be only an approximation.

${ }^{8}$ U.S. Buread of the Census, Benevolent Institutions igio (igi3).
} 
the difference between these two figures is accounted for by proprietary hospitals, then they numbered about 244 hospitals or about fifty-six per cent of total hospitals. This figure must be viewed sceptically, but it is all we have to go on. ${ }^{9}$ By I928 Rorem reported 2435 proprietary out of 6852 total hospitals (thirty-six per cent of all hospitals). ${ }^{10}$ This percentage figure has been declining fairly steadily to the present. In 1968 proprietary hospitals accounted for 10.8 per cent of all hospitals. ${ }^{11}$ The available trend data are set forth in Table I.

TABLE I

The Changing Share of the Market Served by Proprietary Hospitals

\begin{tabular}{|c|c|c|c|}
\hline Year & $\begin{array}{l}\text { Total Number } \\
\text { of Hospitals } \\
\text { of All Types }\end{array}$ & $\begin{array}{l}\text { Number of } \\
\text { Proprietary } \\
\text { Hospitals }\end{array}$ & $\begin{array}{c}\text { Proprietary Hospitals } \\
\text { as a Percent of Total } \\
\text { Hospitals }\end{array}$ \\
\hline 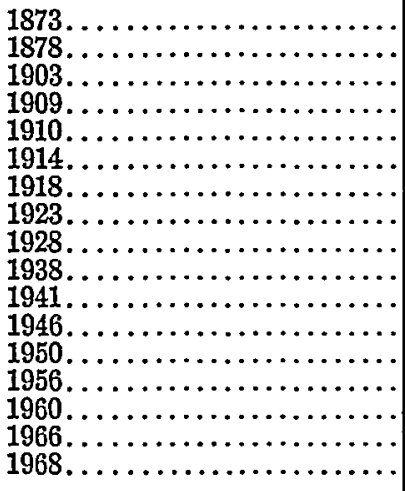 & $\begin{array}{r}178 \\
442 \\
2500 \\
4359 \\
\\
5047 \\
5323 \\
6830 \\
6852 \\
6166 \\
6358 \\
6125 \\
6788 \\
6966 \\
6876 \\
7160 \\
7137\end{array}$ & $\begin{array}{l}2441 \text { (est.) } \\
\\
\\
2435 \\
1681 \\
1584 \\
1076 \\
1218 \\
981 \\
856 \\
852 \\
769\end{array}$ & $\begin{array}{l}56 \% \text { (est.) } \\
\\
36 \% \\
27 \% \\
25 \% \\
18 \% \\
18 \% \\
14 \% \\
12 \% \\
12 \% \\
11 \%\end{array}$ \\
\hline
\end{tabular}

Source: Authorities cited notes $5-8,10$ \& 11 stupra

Where data are available both the proprietary share of the short-term hospital market and the share of the market of proprietary hospitals as measured by number of beds show the same declining trend over time. Diferent sources cite different numbers of hospitals for the same year, making for some confusion in this literature. Definitions have changed slightly orer the years. There are particular difficulties for the years 1945-50 when the AMA stopped listing hospitals and the ABA started.

After Igio the growth in number of hospitals leveled off considerably. The trend away from proprietary hospitals was evident to a few observers by I920, as the following editorial of that year suggests:

The head of a private (for profit) hospital in a Southwestern city recently asked Hospital Management to publish an editorial dealing with the transition through which many hospitals in that section are going.

When the country was new, and before the great prosperity that has come to the Southwest increased wealth and population, the only available hospital facilities were those provided by the physicians and surgeons themselves. It was obviously a period when the private hospital was not only needed, but when it was the only

\footnotetext{
${ }^{\circ}$ It may be close to impossible to obtain more accurate information for these years. Even an indepth study of one area would be inappropriate because of important regional differences. And looking at the history of presently existing hospitals is also inadequate since many of the early proprietary hospitals have disappeared.

${ }^{10}$ C. Rorem, The Public's Investment in Hospitals i4 (I930).

${ }^{11}$ Hospitals (Guide Issue), Aug. I, I969, pt. 2, at 474. This source provides the data for I946-68.
} 
kind of hospital people could possibly get. Because communities lacked the money and the public sentiment that make public hospitals possible the doctors established and operated them as private institutions-through them rendered valuable service to their communities.

Now many of the towns in the Southwest, notably Oklahoma and Texas, have reached a point where they are in a position to establish community hospitals. Their people are ready to support the work and are prepared to take over the private hospitals which have been serving a useful and essential purpose.

That is what is happening. The hospital man referred to above has been asked to allow his institution to become a nucleus around which a community hospital may be built, and he has consented to the plan. His interest is in having hospital facilities for his patients rather than having a hospital that he may call his own. The situation is interesting in emphasizing the important work of the private hospital and in showing how it is often the predecessor and forerunner of the community hospital. The work done by the medical men who established private hospitals when no other hospitals were available forms a commendable and interesting chapter in the development of the American hospital field. ${ }^{12}$

If we might generalize from the foregoing findings, the period r8go to rgro saw a rapid growth in demand for completely new hospitals for paying patients. In the absence of an existing hospital, or in the face of a lack of community effort, proprietary hospitals grew rapidly in number. As growth in the number of institutions stabilized, the proprietary hospitals tended either to become nonprofit or close down. Increases in demand since then have largely resulted in increases in the size of existing hospitals rather than in the number of hospitals.

This gives a basis for the development of a model of the role of proprietary hospitals which will be elaborated and further tested below. ${ }^{13}$

\section{II}

\section{Current Characteristics of Proprietary Hospitals}

This section attempts to paint a statistical portrait of proprietary hospitals today. Table 2 displays some of the major attributes of the three primary types of shortterm, general hospitals. Proprietary hospitals tend to be smaller than voluntary and state and local governmental hospitals and lower in nearly every measure except the excess of revenue over expense. Perhaps the most striking difference is in assets per bed, where voluntary hospitals have, on average, over two and a half times the assets per bed of proprietary hospitals.

\footnotetext{
${ }^{12}$ Hospitaz Management, Feb. I928, at 50.

${ }^{13}$ It is beyond the scope of this paper to discuss the nursing home industry. Based on the historical evidence for hospitals, one can speculate that the rapid growth of nursing homes in the last 30 years is analogous to the rapid growth of hospitals between 1880 and r9ro. Nursing homes at present are largely proprietary, a fact consistent with our model's suggestion that proprietary organizations adapt more rapidly to new demand. One might predict that, once this demand has stabilized, nonprofit nursing homes will have a larger share of the market. See Eagle, Nursing Homes and Related Facilities: $A$ Review of the Literature, 83 Pus. Hearth Rep. 673 (I968); Solon \& Bancy, Ownership and Size of Nursing Homes, 70 PuB. Health Rep. 437 (1955); Earle, The Nursing Home Industry, Hospitals, Feb. 16,1970 , at 45,116 , Mar. 1,1970 , at 60 .
} 
TABLE 2

Selected Characteristics of Nonfederai, Short-term General and Other Special Hospitals, ig68

\begin{tabular}{|c|c|c|c|}
\hline Characteristic & Voluntary & Proprietary & $\begin{array}{l}\text { State \& Local } \\
\text { Governmental }\end{array}$ \\
\hline 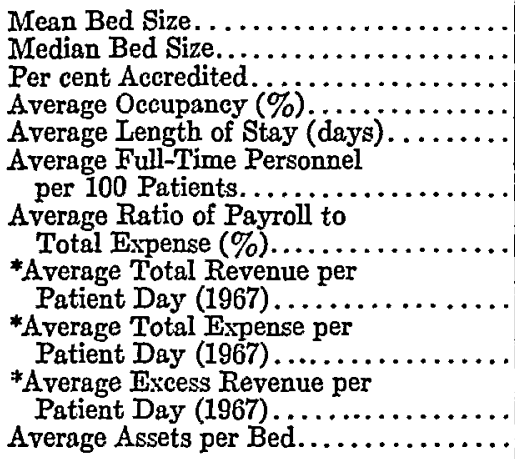 & $\begin{array}{c}165 \\
115 \\
81 \\
80.0 \\
8.3 \\
276 \\
59.9 \\
\$ 57.1 \\
\$ 55.0 \\
\$ 2.1 \\
\$ 29,954\end{array}$ & $\begin{array}{c}62 \\
47 \\
47 \\
73.9 \\
7.0 \\
237 \\
52.2 \\
\$ 56.6 \\
\$ 51.9 \\
\$ 11,229\end{array}$ & $\begin{array}{c}118 \\
89 \\
55 \\
73.9 \\
8.9 \\
270 \\
60.6 \\
\text { n.a. } \\
\$ 51.8 \\
\text { n. a. } \\
\$ 22,323\end{array}$ \\
\hline
\end{tabular}

Source: Hosptrars (Gome Issuz), Aug. 1, 1969, pt. 2, at 475-500, Aug. 1, 1968, pt. 2, at 442, 454.

* Comparable data not available for 1968 .

TABLE 3

Percentage of Hospitals Accredited by the Joint Commission on Accreditation of Hospitals, rg68*

\begin{tabular}{|c|c|c|c|c|}
\hline \multirow[b]{2}{*}{ Size (Beds) } & \multicolumn{2}{|c|}{ Voluntary Hospitals } & \multicolumn{2}{|c|}{ Proprietary Hospitals } \\
\hline & Number & $\%$ Accredited & Number & $\%$ Accredited \\
\hline 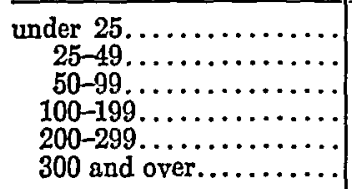 & $\begin{array}{l}155 \\
596 \\
795 \\
854 \\
460 \\
570\end{array}$ & $\begin{array}{l}3.2 \\
47.1 \\
81.5 \\
96.9 \\
98.9 \\
99.5\end{array}$ & $\begin{array}{r}148 \\
276 \\
213 \\
105 \\
22 \\
5\end{array}$ & $\begin{array}{r}2.7 \\
29.7 \\
73.2 \\
87.6 \\
100.0 \\
80.0\end{array}$ \\
\hline Totals. . & 3430 & 81.1 & 769 & 46.8 \\
\hline
\end{tabular}

Source: Hosprrazs (Gudve Issoz), Aug. 1, 1969, pt. 2, at 494. * Hospitals reporting.

One must be very careful in drawing conclusions from Table 2 because many of the apparent differences shown here between types of hospitals can be explained by differences in mean hospital size as measured by the number of beds. Large hospitals have generally higher occupancy, longer length of stay, a higher staffing ratio, higher expense and revenue per patient day, and higher assets per bed. For example, Table 3 demonstrates that, when size is controlled for, there is not too much difference in the percentage of proprietary and nonproprietary hospitals which are accredited. Accreditation is by the Joint Commission on Accreditation of Hospitals and results from periodic inspections of participating hospitals to see if they comply with the Commission's minimal standards of excellence. As such, 
TABLE $_{4}$

Distribution of Nonfederal Hospitals by Bed Size, I968*

\begin{tabular}{|c|c|c|c|c|c|c|}
\hline \multirow[b]{2}{*}{ Size (Beds) } & \multicolumn{2}{|c|}{ Voluntary } & \multicolumn{2}{|c|}{ Proprietary } & \multicolumn{2}{|c|}{$\begin{array}{l}\text { State \& Iocal } \\
\text { Governmental }\end{array}$} \\
\hline & Number & $\%$ & Number & $\%$ & Number & $\%$ \\
\hline 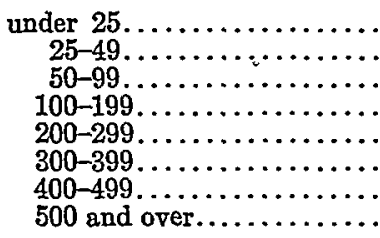 & $\begin{array}{l}155 \\
596 \\
795 \\
854 \\
460 \\
291 \\
141 \\
138\end{array}$ & $\begin{array}{r}4.5 \\
17.4 \\
23.2 \\
24.9 \\
13.4 \\
8.5 \\
4.1 \\
4.0\end{array}$ & $\begin{array}{r}148 \\
276 \\
213 \\
105 \\
22 \\
\\
5\end{array}$ & $\begin{array}{r}19.2 \\
35.9 \\
27.7 \\
13.7 \\
2.9 \\
0.7\end{array}$ & $\begin{array}{r}142 \\
523 \\
469 \\
273 \\
84 \\
39 \\
28 \\
63\end{array}$ & $\begin{array}{r}8.8 \\
32.3 \\
28.9 \\
16.8 \\
5.2 \\
2.4 \\
1.7 \\
3.9\end{array}$ \\
\hline Total. & 3430 & 100.0 & 769 & 100.0 & 1621 & 100.0 \\
\hline $\begin{array}{l}\text { Interquartile Range } \dagger \\
\text { (number of beds):. }\end{array}$ & & & & & & \\
\hline
\end{tabular}

Source: Hosprisars (Guide IssuE), Aug. 1, 1969, pt. 2, at 494. Totals may not be exact due to rounding.

fThis is a simple measure of dispersion. Twenty-five per cent of the hospitals were smaller and $25 \%$ were larger than tho range shown here.

TABLE 5

Regional Distribution of Nonfederal, Short-term General and

Other Spectar Hospitals, I968

\begin{tabular}{|c|c|c|c|}
\hline Region & $\%$ Voluntary & $\%$ Proprietary & $\begin{array}{c}\text { \% State \& } \\
\text { trocal Governmental }\end{array}$ \\
\hline 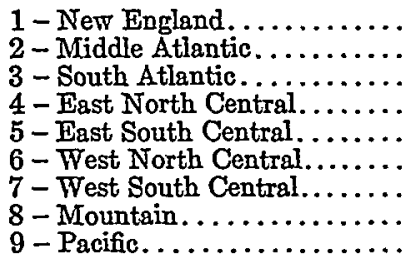 & $\begin{array}{l}87.5 \\
78.7 \\
53.1 \\
75.6 \\
38.6 \\
62.3 \\
34.1 \\
59.7 \\
50.8\end{array}$ & $\begin{array}{r}3.4 \\
10.9 \\
13.2 \\
1.9 \\
17.6 \\
3.2 \\
31.7 \\
5.1 \\
24.3\end{array}$ & $\begin{array}{r}9.1 \\
10.4 \\
33.7 \\
22.5 \\
43.8 \\
34.5 \\
34.2 \\
35.2 \\
24.9\end{array}$ \\
\hline United States Total... & 58.9 & 13.2 & 27.9 \\
\hline
\end{tabular}

Soutce: Hospritas (Gume Issuz), Aug. 1, 1969, pt. 2, at 480-91. Their definition of regions is used here.

it can be used for our purposes as an approximate measure of the quality of care provided by a class of hospitals.

Table 4 gives the size distribution of the three classes of hospitals. Proprietary hospitals tend to be, on average, about two-fifths the size of voluntary hospitals and about one-half the size of state and local governmental hospitals. Proprietary hospitals have the least dispersion in bed size and voluntary hospitals the most.

Table 5 gives the distribution of hospitals by geographical region. Proprietary hospitals tend to be concentrated in certain areas of the country. In fact, nearly two-thirds (sixty-four per cent) of proprietary hospitals are located in five states: Texas, California, New York, Louisiana, and Tennessee. Ten states (including five in New England) and the District of Columbia have no proprietary hospitals. 
TABLE 6

Changes in Selected Characterustics of Nonfederal, Short-term General and Other Special Hospitals, $x 960-1968$

\begin{tabular}{|c|c|c|c|}
\hline \multirow[b]{2}{*}{ Characteristic } & \multicolumn{3}{|c|}{$\%$ Increase (Decrease) } \\
\hline & Voluntary & Proprietary & $\begin{array}{l}\text { State \& Local } \\
\text { Governmental }\end{array}$ \\
\hline 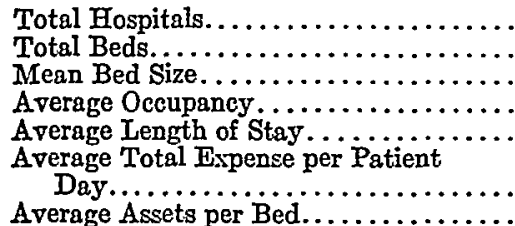 & $\begin{array}{r}4.2 \\
26.9 \\
21.3 \\
4.4 \\
12.2 \\
87.1 \\
58.6\end{array}$ & $\begin{array}{l}(10.2) \\
29.7 \\
44.2 \\
13.0 \\
22.8 \\
79.1 \\
71.0\end{array}$ & $\begin{array}{r}28.7 \\
23.1 \\
(4.8) \\
3.2 \\
1.1 \\
104.7 \\
58.9\end{array}$ \\
\hline
\end{tabular}

Source: Hosprtars (GUDE IssUE), Aug. 1, 1969, pt. 2, at 475.

One can only speculate on these wide regional and state differences. Perhaps they are due in part to differing regional preferences which occurred in the past and have been perpetuated into the present, and in part to differing taxation and licensure policies at the state and local level. They may also be due to regional differences in factors influencing the "market" for short-term hospital care which will be discussed later.

Thus far, the description of proprietary hospitals has been a static one. Table 6 shows some changes in characteristics of short-term hospitals that have occurred in recent years. In the nine-year interval recorded, the total number of proprietary hospitals has decreased about ten per cent while the total number of proprietary beds has increased nearly thirty per cent. The mean bed size of proprietary hospitals has increased over twice as much as that of voluntary hospitals, while state and local governmental hospitals have actually decreased in average bed size. The large increases in average occupancy and average length of stay in proprietary hospitals reflect the relatively low averages for these measures in Ig60 (65.4 per cent and 5.7 days). It is interesting to note that all the characteristics of proprietary hospitals measured here, with the exception of total expense per patient day, have been moving closer to the means of these measures for voluntary hospitals. This is suggestive that hospitals are becoming more homogeneous, but it is certainly not conclusive.

Table 7 illustrates one aspect of proprietary hospitals which has not been mentioned heretofore, namely the relative frequency with which proprietary hospitals enter into and exit from the acute care marketplace. In I968, proprietary hospitals accounted for 13.2 per cent of all short-term general hospitals, yet from I960 to I968, fifty-nine per cent of all the hospitals that closed were proprietary. Similarly, thirty-seven per cent of the hospitals that opened were proprietary.

The volatility of the proprietary hospital market goes hand in hand with their relatively low average bed size and assets per bed. Since proprietary have on 
TABLE 7

Closures and Openings of Nonfederal Short-term General and Other Spectal Hospitals, Ig62-Ig68

\begin{tabular}{|c|c|c|c|c|}
\hline & Voluntary & Proprietary & $\begin{array}{l}\text { State \& Local } \\
\text { Governmental }\end{array}$ & Total \\
\hline 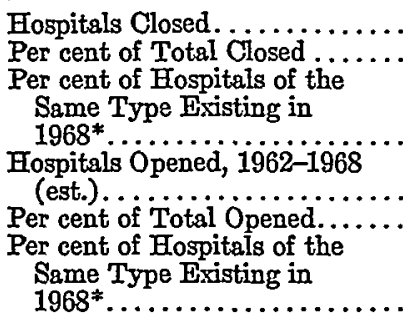 & $\begin{array}{l}247 \\
26 \% \\
\\
7 \% \\
393 \\
30 \% \\
\\
12 \%\end{array}$ & $\begin{array}{l}561 \\
59 \% \\
73 \% \\
476 \\
37 \% \\
62 \%\end{array}$ & $\begin{array}{r}146 \\
15 \% \\
\\
9 \% \\
423 \\
33 \% \\
\\
26 \%\end{array}$ & $\begin{array}{l}954 \\
100 \% \\
\text { n.a. } \\
1292 \\
100 \% \\
\text { n.a. }\end{array}$ \\
\hline
\end{tabular}

Source: Hosprratus (Gorbe Issoz), Aug. 1, 1969, pt. 2, at 475; AHA Bureau of Research Statisties, Trends in Hospital Mergers, Closures, and Services, tables 9 \& 10 . Aug. 5,1968 (unpublished document)

"This statistic is intended to give a rourg idea of the masnitude of closyre or opening with respect to the shasoluto hospital class sive (e.g., the number of proprietary hospitals that closed from 1902 to 1988 is $73 \%$ of the total number of proprictary bospitals that oxisted in 1988).

average about two-fifths the beds of voluntary hospitals and two-fifths the assets per bed, the typical proprietary hospital has less than one-sixth the total assets per hospital of a typical voluntary hospital. Entry into and exit from the marketplace involves the purchase and sale of far fewer assets. ${ }^{14}$ In short, proprietary hospitals are much more easily adaptable to changes in the market for acute hospital care. This conclusion is certainly consistent with the historical role of the proprietary hospital discussed previously. Tables 8-ro focus more closely on proprietary hospitals alone.

Table 8 shows some of the results of our study of all the short-term proprietary hospitals of record in 1960 and their status in 1967 . New proprietary hospitalsthose that existed in 1967 but did not exist in Ig6o-were also recorded. All proprietary hospitals that opened after $x 960$ but closed or otherwise changed their status (became voluntary, for example) were not considered.

The hospitals are listed by increasing complexity of proprietary ownership, with single ownership as the least complex. The five possible outcomes of these hospitals were (i) to remain the same; (ii) and (iii) to change to one of the two other forms of proprietary ownership; $;^{15}(i v)$ to close; or $(v)$ to become voluntary. The results shown in Table 8 are summarized below:

(I) Singly-owned hospitals had the highest proportion that closed (fifty-one per cent) and the lowest proportion that became voluntary (four per cent).

\footnotetext{
14 The principal also applies to hospitals of equal size. Richard L. Johnson has estimated that the cost of construction was nearly three times as great for a "typical" roo-bed voluntary hospital as for a "typical" proprietary hospital of the same size. R. Johnson, Capital Financing of Proprietary Hospitals, I967 (unpublished manuscript).

${ }_{15}$ Thus a singly-owned hospital could pass to partnership or corporate status; a corporate-owned hos. pital could become singly- or partnership-owned; and a partnership operation could pass to a single owner or to corporate form.
} 
TABLE 8

Ownership Changes for Proprietary Hospitals, x960-ig67

\begin{tabular}{|c|c|c|c|c|c|c|c|c|c|c|c|c|}
\hline \multirow{3}{*}{$\begin{array}{l}\text { Ownership in } \\
\text { 1960: }\end{array}$} & \multicolumn{12}{|c|}{ Ownership in 1967} \\
\hline & \multicolumn{2}{|c|}{$\begin{array}{l}\text { Single } \\
\text { Owner }\end{array}$} & \multicolumn{2}{|c|}{ Partnership } & \multicolumn{2}{|c|}{$\begin{array}{l}\text { For-Profit } \\
\text { Corporation }\end{array}$} & \multicolumn{2}{|c|}{ Closed } & \multicolumn{2}{|c|}{$\begin{array}{l}\text { Became } \\
\text { Voluntary }\end{array}$} & \multicolumn{2}{|c|}{ Total } \\
\hline & numb & $\% \%$ & numbe & er $\%$ & numbe & $\%$ & numbe & $\%$ & numbe & $\%$ & numb & ber $\%$ \\
\hline Single Owner & 60 & 90 & 12 & 5 & 33 & & 120 & & 9 & & 234 & \\
\hline Partnership & 6 & & 88 & & 20 & & 84 & & 14 & & 212 & \\
\hline Corporation & 5 & 0 & 8 & 41 & 282 & & 85 & & 55 & & 435 & (100) \\
\hline & & & - & & - & & & & & & - & \\
\hline $\begin{array}{l}\text { Total hospitals } \\
\text { existing in } 1960\end{array}$ & 71 & 8 & 108 & 12 & 335 & 38 & 289 & 33 & 77 & 9 & 881 & (100) \\
\hline $\begin{array}{l}\text { Hospitals } \\
\text { opened since }\end{array}$ & 33 & 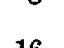 & 50 & 12 & 240 & & & & & & 323 & (10) \\
\hline 1960 & - & 10 & - & 10 & - & $14 x$ & & & & & - & (100) \\
\hline $\begin{array}{l}\text { Total all } \\
\text { hospitals in } \\
\text { existence in } \\
1967\end{array}$ & 104 & 12 & 158 & 19 & 575 & 69 & & & & & 837 & $(100)$ \\
\hline
\end{tabular}

Source: Hozpitaus (GJibe Issuz), Aug. 1, 1961, pt. 2, Aug. 1, 1968, pt. 2. Alaska and Hawaii are excluded.

Corporate-owned hospitals had the lowest proportion that closed (nineteen per cent) and the highest proportion that became voluntary (thirteen per cent). Partnership-owned hospitals were in the middle on both counts (forty per cent closed and seven per cent became voluntary).

(2) Very few hospitals reverted toward a "lower" level of ownership. Table 8 shows that only three per cent of partnership-owned hospitals reverted to single ownership, and only one per cent of corporate-owned hospitals reverted to a single owner and two per cent to a partnership. Singly-owned hospitals had the smallest proportion that remained the same (twenty-eight per cent) while the corporateowned category had the highest (sixty-five per cent). Partnership-owned hospitals were in the middle (forty-one per cent).

(3) Of the 88I proprietary hospitals existing in 1960 , thirty-three per cent had closed and nine per cent had become voluntary by 1967 . Therefore, fifty-eight per cent of proprietary hospitals in Ig6o were still proprietary in 1967.

(4) In I960, twenty-seven per cent of proprietary hospitals were singly-owned, twenty-four per cent were partnership-owned, and forty-nine per cent were corporateowned. The corresponding figures for 1967 (including new proprietary hospitals) were twelve, nineteen, and sixty-nine per cent, respectively. Thus there is a pronounced trend toward corporate ownership of proprietary hospitals.

(5) The data suggest a stepwise trend from single owner and partnership to forprofit corporation-and finally to voluntary corporation. Singly- and partnershipowned hospitals are more likely to become corporation-owned hospitals than voluntary hospitals. Corporation-owned hospitals are by far the most likely to 
become voluntary-thirteen as opposed to five per cent for the other two types combined; if one considers only those hospitals which did not close, the corresponding figures are sixteen and nine per cent, respectively.

These data do not measure the dynamics of the proprietary hospitals marketplace between 1960 and 1967 . For example, a hospital that entered as singlyowned in, say, 1963 and became corporate-owned in 1966 would be listed as entering as a corporation. A hospital that was listed as singly-owned in rg6o which became a corporation in 1965 and a voluntary hospital in 1967 would be listed simply as a singly-owned hospital that became voluntary. A hospital that entered as a corporation in 1965 and became voluntary in 1967 would not be recorded at all.

Although these dynamic interim effects have not been recorded, one can obtain an idea as to their magnitude if Table 7 is reconsidered. The AHA Bureau of Research Statistics reported that between 1962 and 1968 a total of $56 \mathrm{x}$ proprietary hospitals closed. ${ }^{16}$ Table 8 shows that of the proprietary hospitals existing in 1960 , 289 had closed by 1967 . Aside from the fact that slightly different time periods are used, the difference between these two figures should be explained by the fact that the data expressed in Table 7 measure the interim effects, while the data expressed in Table 8 do not. ${ }^{17}$ Thus a proprietary hospital that was opened in I963 and closed in I966 would be recorded in Table 7 but not in Table 8. These data suggest that Table 8 conceals some of the activity in ownership change of proprietary hospitals.

The relationship between change in type of proprietary hospital ownership and change in average size (in beds) is presented in Tables 9 and ro. The data in these tables are summarized below:

(I) Although the total number of proprietary hospitals declined by five per cent, the number of corporate-owned proprietary hospitals increased by thirty-two per cent. The percentage of decline in individually-owned hospitals was over twice as great as that in the number of partnership-owned hospitals. The trend toward corporate ownership of proprietary hospitals is clearly established.

(2) In 1967 as in 1960 , corporate-owned proprietary hospitals had the highest average bed size and singly-owned hospitals the lowest. In both years the average size of corporate hospitals was over twice as great as that of individually-owned hospitals.

(3) Each type of proprietary hospital increased in average size (as measured by the number of beds) from I960 to I967, with partnership-owned hospitals in-

\footnotetext{
${ }^{10}$ AHA Bureau of Research Statistics, Trends in Hospital Mergers, Closures, and Services, Aug. 5, I968 (unpublished document).

${ }^{17}$ One cannot dismiss the possibility that the difference is also largely due to the vagaries of data collection. The AHA Bureau of Research Statistics did not report a source for its data on hospital closures, but presumably it used the same data base from which the Guide Issties are compiled. If this is so, tables 7 and 8, supra, should be consistent and comparable. Interestingly, the Bureau reported that of all proprietary hospital closures between 1962 and $1968,34 \%$ occurred in 1965 , a year considered in both tables.
} 
TABLE 9

Change in OWnership of Proprietary Hospitals, ig6o-rg67

\begin{tabular}{|c|c|c|c|c|c|}
\hline \multirow[b]{2}{*}{ Type of Ownership } & \multicolumn{2}{|c|}{1960} & \multicolumn{2}{|c|}{1967} & \multirow{2}{*}{$\begin{array}{l}\text { Percentage } \\
\text { Change } \\
\text { in Numbe }\end{array}$} \\
\hline & Number & Percentage & Number & Percentage & \\
\hline $\begin{array}{l}\text { Single Owner } \ldots \ldots \ldots \ldots \\
\text { Partnership. . . . . . . } \\
\text { Corporation } . \ldots \ldots \ldots\end{array}$ & $\begin{array}{l}234 \\
212 \\
435\end{array}$ & $\begin{array}{l}27 \\
24 \\
49\end{array}$ & $\begin{array}{l}104 \\
158 \\
575\end{array}$ & $\begin{array}{l}12 \\
19 \\
69\end{array}$ & $\begin{array}{r}-56 \\
-25 \\
32\end{array}$ \\
\hline Total... & 881 & 100 & 837 & 100 & -5 \\
\hline
\end{tabular}

Source: Data presented in Table 8.

TABLE Io

Change in Average Size (Number of Beds) of Proprietary Hospitals, ז960-тg67

\begin{tabular}{|c|c|c|c|}
\hline \multirow[b]{2}{*}{ Type of Ownership } & \multicolumn{2}{|c|}{ Average Size } & \multirow{2}{*}{$\begin{array}{l}\text { Percentage } \\
\text { Increase }\end{array}$} \\
\hline & 1960 & 1967 & \\
\hline 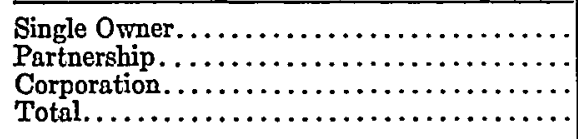 & $\begin{array}{l}26.1 \\
34.1 \\
58.0 \\
43.8\end{array}$ & $\begin{array}{l}30.4 \\
57.6 \\
65.2 \\
59.4\end{array}$ & $\begin{array}{l}16 \\
69 \\
12 \\
36\end{array}$ \\
\hline $\begin{array}{l}\text { Proprietary hospitals that closed by } 1967 \ldots \\
\text { Proprietary hospitals that became voluntary } \\
\text { by } 1967 .\end{array}$ & $\begin{array}{l}30.5 \\
56.3\end{array}$ & - & - \\
\hline $\begin{array}{l}\text { All nonfederal short-term general and } \\
\text { other special hospitals.................. }\end{array}$ & 118.2 & 134.7 & 14 \\
\hline
\end{tabular}

Sourec: Hogprtars (Guide Issur), Aug. 1, 1961, pt. 2, Aug. 1, 1968, pt. 2.

creasing by the greatest percentage. Due to the general trend toward higher average size and the fact that many singly- and partnership-owned hospitals moved into the higher average size corporation class, the average size of all proprietary hospitals increased by thirty-six per cent. By comparison, the average size increase for all nonfederal, short-term general and other special hospitals was only fourteen per cent.

(4) The average size of proprietary hospitals existing in I960 that had closed by 1967 was 30.5 beds. This figure compares with an average size of about sixty beds for all short-term hospitals (including federal) that closed between 1962 and Ig68. ${ }^{18}$

Not shown in Table to is the fact that the average sizes for proprietary hospitals that closed and for those that became voluntary were highest for corporateowned hospitals and lowest for individually-owned hospitals, with partnershipowned hospitals in the middle in both cases.

\footnotetext{
${ }^{18}$ This figure is estimated from data presented in Trends in Hospital Mergers, Closures, and Services, supra note 16 , table 6 .
} 
One final analysis was performed in order to gain further insight into the proprietary role in the market for acute hospital care. Readings were taken from 196r and rg68 Guide Issues on the ratio of proprietary hospital beds to all nonfederal, short-term general and other special hospital beds for each of forty-eight states for the years $I 960$ and 1967 . A regression equation was estimated with the change in the proportion of proprietary beds to total beds as the dependent variable $(Y)$. Several variables were tried as independent, the most satisfactory of which were the ratio of growth of population by state $\left(\mathrm{X}_{1}\right)$ and the proportion of growth in per capita income by state $\left(X_{2}\right)$. The equation derived is given below: ${ }^{10}$

$$
\begin{aligned}
& \mathrm{Y}=.00 \mathrm{r}+. \mathrm{rrr} \mathrm{X}_{1}-.093 \mathrm{X}_{2} \\
& \mathrm{t} \text {-values } \quad(4.084) \quad(-3.135) \quad r^{2}=0.495
\end{aligned}
$$

The coefficient of determination $\left(r^{2}\right)$ of .495 means that nearly half of the variation in the proportion of proprietary beds to total beds by state is explained by variations in the proportionate changes in population and per capita income. The positive sign of the coefficient of $\mathrm{X}_{1}$ means that increases in the ratio of proprietary beds to total beds are highest in states where population has increased the most. The negative sign of the coefficient of $\mathrm{X}_{2}$ indicates that increases in the ratio of proprietary beds to total beds are highest in states where per capita income has increased the least.

To interpret this regression equation, one should bear in mind that we have considered only the proportionate changes in the measures considered and not their absolute levels. The positive relationship between population change and change in market share is clear cut. Proprietary hospitals have proliferated where the demand for hospital beds, as approximated by population growth, has outstripped the capacity of the nonprofit system to accommodate the increase in demand. The negative relationship between growth in per capita income and change in market share is less obvious. Our interpretation is that proprietary hospital beds tend to proliferate where there has been inadequate financing of capital expansion through the voluntary system. Perhaps this condition is most likely to exist in states where per capita income growth has been lowest. A related consideration is that since proprietary hospital beds require the formation of much less capital than nonprofit hospital beds, states in which income has increased the least are less likely to concentrate on the more expensive type of facility.

In the light of these data and experiments one can postulate a partial and tenta-

\footnotetext{
${ }^{10}$ The variables were defined in the following manner:

$\mathrm{Y}=\frac{\text { proprietary beds, } 1967}{\text { total beds, } 1967}-\frac{\text { proprietary beds, } 1960}{\text { total beds, } x 960}$

$\mathrm{x}_{1}=\frac{\text { population, } 1967-\text { population, } 1960}{\text { population, } 1960}$

$\mathrm{x}_{2}=\frac{\text { per capita income, } 1967-\text { per capita income, } 1960}{\text { per capita income, } \mathrm{x} 960}$
} 
tive model of the role of proprietary hospitals in the market for acute hospital care. We have observed that proprietary hospitals constitute a "marginal" operation; marginal with respect to their small share of the market, their small average bed size, their quick entry and exit from the marketplace, and a variety of other factors. Certainly, the market is heavily dominated by nonprofit hospitals, and this is reflected by the apparent fact that most public policy in the hospital area seems to be formulated with the nonprofit hospital specifically in mind. This predominance of voluntarism occurs in an economy that depends primarily on the profit motive for the organization of production in nearly all other industries. Economist Kenneth Arrow notes that apparent anomaly in the following terms:

Departure from the profit motive is strikingly manifested by the overwhelming predominance of nonprofit over proprietary hospitals... The simplest explanation is that public and private subsidies decrease the cost to the patient in nonprofit hospitals. A second possibility is that the association of profit-making with the supply of medical services arouses suspicion and antagonism on the part of patients and referring physicians, so they do prefer nonprofit institutions. Either explanation implies a preference on the part of some group, whether donors [sic] or patients, against the profit motive in the supply of hospital services. ${ }^{20}$

Given this apparent disdain for proprietary hospitals and its manifestations (especially in the area of taxation), why do proprietary hospitals persist? To answer this question one must examine the motives behind the construction and operation of individual proprietary hospitals. The literature suggests that these hospitals are most often created for one of two primary reasons: (I) Individual entrepreneurs have perceived the attractiveness of a proprietary hospital as a profitable investment venture in communities in which, for a variety of reasons, nonprofit hospitals have not satisfied the demand for acute hospital care; or (2) individual doctors or small groups of doctors have become dissatisfied with the lack of availability of beds for admitting their private patients and have responded by financing the construction of their own proprietary hospitals.

In some parts of the country, such as New York City, it is widely believed that proprietary hospitals exist there because many doctors have been unable to obtain admitting privileges at the often more prestigious voluntary hospitals. Some argue that they have not been granted privileges at voluntary hospitals because they are less competent, while others argue that discrimination has been a factor. The former argument has led to the belief that doctors affiliated with proprietary hospitals are less competent and that, therefore, the quality of care at these hospitals is not as good.

Both of these explanations imply failure on the part of nonprofit hospitals to accommodate changes in the demand for acute hospital care. In a world where demand was stable or entirely predictable we might expect proprietary hospitals

\footnotetext{
${ }^{30}$ Arrow, Uncertainty and the Welfare Economics of Medical Care, 53 AMr. Econ. REv. 94I, 950 (r963) (footnotes omitted).
} 
to die out entirely. The data have shown that proprietary hospitals tend to close or become voluntary where communities have stabilized and the demands for acute hospital care have become relatively known. But, where such conditions have not been present, proprietary hospitals have taken advantage of their ability to enter quickly into the market place in response to changing conditions affecting the demand for acute hospital care. In short, the flexibility of the proprietary hospital operation has contributed to its ability to compete in a market dominated by nonprofit hospitals.

The above "model" of proprietary hospital operation tends to be supported by the data. It assigns a role to proprietary hospitals that is more complementary than competitive with respect to the nonprofit sector. Proprietary hospitals are seen to act as a buffer to the dominant mode of nonprofit operation, taking up the peaks and troughs of a capricious demand for acute hospital care. ${ }^{21}$ This role of proprietary hospitals will be discussed more fully in the next section of the paper, which attempts to summarize the salient issues and trends that involve the profit motive in the hospital industry.

\section{III}

\section{Issues}

Of the many issues relevant to proprietary hospitals only a few will be discussed here. These are professional ideology, proprietary chains, selective admissions (called "cream-skimming"), and proprietary versus voluntary hospitals.

\section{A. Ideology}

In a country committed to competitive capitalism, why are not all hospitals proprietary? This inquiry soon takes us into questions far from the core of our paper, but a brief comment may be useful.

The underlying assumption of the professions is that they consist of highly trained experts. It follows that the public is ignorant and unable to choose wisely in the professional's area of competence. The professional is expected to make decisions for the unknowing consumer. If the professional is not to abuse this trust, he must be motivated by a high ethical standard rather than the crass pursuit of the dollar. Furthermore, the client's freedom of choice is restricted since lower-quality, "cutrate" services are not provided, even if there is revealed a significant demand for this type of service.

Conversely, the free market and the profit motive assume that the consumer is the best evaluator of his purchases, and the seller is not expected to adhere to a high ethical standard except insofar as his own interests are promoted. The professional

\footnotetext{
\$1 The relatively small share of the market held by proprietary hospitals suggests that these peaks and troughs are proportionally rather small in this industry. They are rather large in the drug industry, and this may explain why the latter industry is dominated by for-profit firms.
} 
provides what the public "needs" while the competitive marketplace provides what the customer "demands."

Given this philosophy of professionalism in medicine, nonprofit status becomes the preferred type of ownership for hospitals because it places ethical service above profits and it results in a vehicle for providing for patient's "needs" rather than being subservient to consumer "demands." In addition, the existence of profits is often viewed as a detraction from the amount of vital health services received for every dollar spent. This effect is magnified by the critical, "life-or-death" nature of the product in the acute hospital care industry. One might alternatively view the existence of profits as evidence of the satisfaction of consumer wants, but this is not the dominant view of the health care industries, except for, perhaps, the case of the individual medical practitioner.

Proprietary hospitals must surmount this ideologically derived distaste for the profit motive in order to reverse the trend toward their disappearance. The historical role of proprietary hospitals is often condoned by the professional elements of the industry on the grounds that they existed primarily where there were no nonprofit hospitals to fulfill community needs. In fact, we have shown that many such hospitals were conceived and operated by the professionals themselves. However, as proprietary hospitals increasingly attempt to enter into direct competition with their nonprofit counterparts, as is sometimes the case with the multi-facility chains, the stigma of the profit motive becomes clearly and volubly expressed.

\section{B. The For-Profit Hospital Chains ${ }^{22}$}

The recent development of publicly owned, for-profit corporations owning a chain of hospitals (and perhaps other health facilities such as nursing homes and laboratories as well) has been of interest to many because of their spectacular and volatile stock market performance. Stock prices of these corporations rose sharply in 1968 and 1969 , so that many were selling at price-to-earnings ratios of roo or more. By 1970, these prices fell sharply, even below their initial offering prices, and more sharply than the stock market as a whole.

As of 1970 there were twenty-nine different chains owning two or more hospitals. The largest two were American Medicorp, Inc., with thirty-one hospitals, and Hospital Corporation of America, with twenty-three hospitals. These twenty-nine corporations owned a total of 207 hospitals in 1970 .

The growth of these chains has primarily occurred through the acquisition of existing proprietary hospitals in exchange for stock in the chain. Given the spectacular rise in prices of these stocks, this transaction must have been appealing to existing owners, thus spurring the rapid growth of the chains. As most of the potentially profitable existing proprietary hospitals have now either been purchased by a chain or have declined to sell, this form of growth will probably play a less

\footnotetext{
${ }^{22}$ The data in this section is largely derived from Study of For-Profit Hospital Chains, supra note 4, but the interpretation is our own.
} 
important role in the future. Mark Levitan, an official of American Medicorp, sees their future efforts as concentrated in building new hospitals in new and growing communities rather than in purchasing existing hospitals. ${ }^{23}$

It is too early to tell how important a role these chains will play in the hospital industry. They are currently in a transition period reflected by the recent decline in their stock prices and by the end of the period of growth through the acquisition of existing proprietary hospitals. Thus their future is uncertain. Given our model, one might predict a continued existence for the chains as they fill the traditional role of proprietary hospitals, rapidly adapting to shifts in demand. One would expect to observe their future expansion through building new hospitals in rapidly growing middle-class communities. Our model would predict neither their disappearance nor their capturing of an enormous share of the total hospital market. To this extent, these chains do not represent a "break in the data" or a departure from our model.

To the extent that the chains have been transforming single-owner and partnership-owned hospitals into corporate-owned hospitals they fit our model. However, the chains may block the final step in the progression should they prove reluctant to turn their largest hospitals over to nonprofit corporations.

The concept of a chain of hospitals within a single corporation is not new. The Veterans Administration hospitals, numerous Catholic orders, and other religious groups own chains of not-for-profit hospitals. The for-profit chains argue that there are economies of scale to be achieved through such combinations. However, the efficiency of the above-mentioned nonprofit chains has not been noticeably greater than that of individual voluntary hospitals, which use consultants, planning groups, and regional hospital associations as a substitute for the staff skills that can be performed by the corporate headquarters of a chain.

The for-profit chains are new in that they are not totally owned by physicians, as has been the case overwhelmingly with the other proprietary hospitals. A potential benefit of this public ownership is the ability to raise capital through issuance of equity shares or convertible bonds. Other than this, these for-profit chains are merely a new combination of old ingredients (multiple ownership, forprofit status), and it remains to be seen if the sum is greater than the parts.

\section{C. "Cream-Skimming"}

The most serious indictment of proprietary hospitals is contained in the argument that has been labeled "cream-skimming." The essence of the cream-skimming argument is that proprietary hospitals can and do profit by concentrating on providing the most profitable services to the best-paying patients, thereby skimming the cream of the market for acute hospital care and leaving the remainder to nonprofit hospitals.

\footnotetext{
${ }^{23}$ Personal communication to the authors.
} 
There are two basic types of cream-skimming. First, with regard to the range of services offered, proprietary hospitals allegedly eliminate, wherever possible, the more expensive and less heavily utilized services which tend to be unprofitable to most hospitals, such as emergency and outpatient departments, pediatric and obstetric units, and cardiac care units. Data support the belief that proprietary hospitals, on average, offer fewer services than nonprofit hospitals, although the differences are reduced when only hospitals of similar size are considered. ${ }^{24}$

Second, proprietary hospitals are accused of skimming the cream by excluding so far as possible patients with complex illnesses who require expensive and timeconsuming treatment and patients who do not pay their full charges-such as Medicare, Medicaid, the uninsured, and most welfare patients. Most of this selecting is accomplished simply by locating the hospital in a relatively well-to-do area and by exercising some control over the admitting practices of the medical staff.

Critics of proprietary hospitals have stated that only by skimming the cream are proprietary hospitals able to compete successfully with their nonprofit counterparts. Hospitals, it is argued, in order to meet the needs of the community must offer a whole range of services, including some which are inherently unprofitable, to all the local populace, regardless of a patient's ability to pay. If the proprietary hospital can exclude unprofitable services and patients, it can then use slightly lower prices or added convenience to attract the profitable patients. This poses a serious threat to competing nonprofit hospitals, because they are deprived of many of their best sources of revenue.

The cream-skimming argument implies that the traditional rate structures of nonprofit hospitals have been set without correspondence to costs. In a competitively stable industry price will equal economic costs (when investment returns are considered an element of cost).

The fact that there are some goods and services in the hospital industry and some types of patients which are "profitable" and some which are not strongly implies a system of price discrimination whereby some patients are overcharged for their hospital care and some are undercharged. The cream-skimming controversy serves to illustrate the existence of noncompetitive conditions in the hospital industry today. The multi-product, multi-service nature of the hospital industry, with the infusion of a myriad of different types of third-party payers, makes pricing extremely difficult for the typical hospital. Nevertheless, if certain types of services are consistently and identifiably overcharged for, nonprofit hospitals have good reason to fear competition from proprietary hospitals.

The attitude of opponents of proprietary hospitals is that such hospitals have no right to rob the nonprofit hospitals of their profitable patients and should be restrained from cream-skimming practices. They further argue that any hospital, regardless of its ownership status, has an intrinsic obligation to its community to

\footnotetext{
"Johnson, supra note 14; Study of For-Profit Hospital Chains, supra note 4.
} 
offer a full range of services to all patients irrespective of their ability to pay. ${ }^{25}$ Defendants of proprietary hospitals, after stating that services are not limited as much as is generally believed, argue that to eliminate cream-skimming practices would restrict both competition and the potential for competition and would reduce the patient's freedom of choice. They further argue that many hospital services are unprofitable primarily because they are underutilized and that proprietary hospitals' provision of such services would amount to unnecessary duplication. With regard to paying for indigent patients, proprietary hospitals claim that, as taxpayers, they should not be required to perform this welfare function and that it is unfair to expect a hospital to provide any service without compensation or at a price lower than its cost.

The cream-skimming controversy has serious implications for policy makers in the area of health care services. Why have voluntary, nonprofit hospitals found it necessary to set rates such that some services are profitable and others unprofitable? In the hospital industry, the individual nonprofit hospital has typically acted as both the arbiter and provider of many measures designed to affect the community's welfare with respect to health. As some services have been regarded as "needed" but too expensive for community members to pay full cost, such services have been underpriced, and, in the case of some medically indigent patients, services have been provided without charge. Deficits for provision of these services have been recovered in part by charging at above cost for the simpler services rendered to patients with less complicated illnesses. This process effects a redistribution of income in favor of the very sick and the inadequately insured at the expense of other hospital patients. Due to broad levels of insurance coverage, this redistribution of income is translated into increased insurance premiums paid by ill and healthy persons alike. It is argued by many economists that this type of decision on the redistribution of income should be performed at some level of government rather than through price discrimination by providers of service.

It is easy to see that widespread competition from proprietary hospitals might jeopardize the nonprofit hospital's pricing structure. This does not necessarily imply, however, that cream-skimming practices by proprietary hospitals should be prohibited. It is by no means clear that discriminatory pricing at the individual hospital level is a desirable method of implementing public policy in the area of health. For one thing, such a system is fragmented and lacks centralized control over the degree and direction of implementation of welfare measures. Also, the potentially salutary effects of competition cannot be disregarded. On the other hand, this type of competition may require new forms of financing for unprofitable hospital services and uninsured patients. Certainly, the resolution of the cream-skimming controversy is a perplexing problem for policy makers and providers of hospital care alike.

\footnotetext{
${ }^{25}$ For a discussion of the hospital's duty to serve, see Cantor, The Law and Poor People's Access to Health Care, in this symposium, p. gor.
} 


\section{Proprietary Versus Voluntary Hospitals}

Why do proprietary hospitals become voluntary? How do the two types compare in performance? We have discussed the proprietary's more rapid adaptation to fluctuating demand, the apparent preference on the part of the public for nonprofit hospitals, ${ }^{26}$ and the ideological preference for them on the part of professionals. Other reasons include opposition to proprietary hospitals by licensing agencies, Blue Cross, and regional hospital planning agencies. This opposition is hard to document, because it would appear through unwritten administrative decisions rather than by legislation or any explicit written policy. ${ }^{27}$

An exhaustive study of these restrictions has not been carried out. One of the few states with legal restrictions is New York, ${ }^{28}$ where proprietary hospitals may be operated by single owners or partnerships but not by a corporation (including chains). This law, in effect, does not allow the natural progression which occurs elsewhere to take place. These administrative practices and legal restrictions are, in a sense, artificial in that there is no compelling natural reason why they should exist.

Another reason for favoring the voluntary hospital is the availability of charitable contributions and the services of volunteer workers. It is not clear how important the effect of charity is here. First, the proportion of hospital costs covered by charity has been declining throughout this century. If charity is important in favoring the notfor-profit hospital, then one would expect to see a historical trend just the reverse of that shown in Table I. If charity was more important fifty years ago, there would have been proportionally more voluntary hospitals then than now. Second, it may be possible for proprietary hospitals to set up not-for-profit corporations with overlapping boards of directors for the receipt of charitable funds-for example, a nonprofit research institute or clinic. And there appears to be no reason why proprietary hospitals cannot use volunteers. Finally, there are the tax advantages accruing to nonprofit corporations, particularly in the form of exemptions from real estate taxes. These may be large and important, but there is no compelling reason why these advantages could not be extended to proprietary hospitals.

To some extent the future of proprietary hospitals will depend on their power to influence planning bodies and lobby effectively for favorable legislation, since legislation is the most likely source of disturbance in the progression suggested by our model.

We have attempted to show that proprietary hospitals "behave" in ways which nonprofit hospitals do not-for example, their greater adaptability to fluctuations

\footnotetext{
${ }^{30}$ One indicator of public preference for the nonprofit hospital is the degree to which proprietary hospitals make an effort to disguise their for-profit status and "masquerade" as nonprofit institutions.

${ }^{27}$ Limited evidence does exist, however. In a study of eight standard metropolitan statistical areas, J. Joel May found that, from 1952 to 1963 , in areas with hospital planning agencies, proprictary hospital beds decreased $54 \%$, whereas in areas without such agencies, proprietary beds increased $222 \%$. J. MAY, Heatti Pianning: Its Past and Potential 63 (ig67).

${ }^{28}$ N.Y. PUb. Heatth LAW $\$ 2801-a$ (McKinney Supp. 1970).
} 
in demand. Conversely, voluntary hospitals perform in ways which proprietary hospitals do not. They are more likely to accept indigent patients; they are more heavily involved in scientific research; and they are more involved in teaching interns, residents, medical students, nurses, and other ancillary professional personnel and in the use of new and complex equipment and treatment techniques. Part of these differences can be accounted for by hospital size. Part can be accounted for by the fact that there is no "paying public" who "buy" enough of these services to make them profitable. Proprietary hospitals, to the extent that they are compelled by the profit motive, will take on these activities only to the exent that they are profitable. $^{29}$

Which type of hospital is more efficient, and which type has the highest quality of care? ${ }^{30}$ The major argument of the proprietary hospitals is that the profit motive provides an incentive for efficiency which does not exist in the voluntary hospital. Opponents argue that the proprietaries make a profit by reducing quality of care and exploiting public ignorance. Efficiency and quality of care are extremely difficult to measure, and so conclusions must be tentative.

If one is willing to accept the Darwinian assumption of survival of the fittest, then the proprietary hospital's declining share of the market suggests its relative inefficiency. ${ }^{31}$ Moreover, there is a consensus that there are economies of scale for up to 250 beds and perhaps beyond. The small average size of proprietary hospitals ${ }^{32}$ implies that individual proprietary hospitals have less opportunity to realize economies of scale and are therefore comparatively inefficient.

There is also a consensus that, on the average, quality of care increases with hospital size. ${ }^{33}$ The is in part due to the wider scope of services and the range of technical personnel that larger hospitals tend to have. This size effect is also reflected in the fact that small hospitals are far less likely to be accredited by the Joint Commission on Accreditation of Hospitals. ${ }^{34}$ To the extent that this is true, the proprietary hospitals, being, on the average, smaller, will provide a lower quality of care.

If one controls for the effect of size, then these differences are much less. Table 3 shows that, controlling for size, proprietary hospitals have almost the same chance

\footnotetext{
${ }^{29}$ Note that for-profit and voluntary hospitals thus innovate in quite different ways. The proprietary hospital and the chains adapt to new demands, while the voluntary hospitals are more likely to support scientific research and pioneer in the use of new treatment techniques and equipment.

${ }^{80}$ The concepts are generally given separate consideration in the hospital field, and we will follow this convention. Efficiency usually refers to costs per unit of service (for example, cost per patient day), controlling for differences in the type of service provided, while quality of care is generally discussed without reference to costs.

s1 See table I supra. For a more complete defense of the "survivorship principle," see Stigler, The Economies of Scale, I J. Law. \& Econ. 54 (1958).

${ }^{82}$ See table 2 stupra.

${ }^{33}$ For a review of the literature on efficiency, quality of care, and hospital size, see D. Ncuhauser \& R. Anderson, Structural Comparative Studies of Hospitals, paper presented at the Conference on Hospital Intraorganizational Research, Ann Arbor, Mich., May 22, 1970.

st See table 3 stupra.
} 
TABLE II

Mean Expense per InPatient Day for Community Hospitals IN I968

\begin{tabular}{|c|c|c|c|}
\hline Number of Beds & Nonprofit & $\underset{\text { Chain }}{\text { For-Profit }}$ & $\begin{array}{l}\text { For-Profit } \\
\text { Nonchain }\end{array}$ \\
\hline 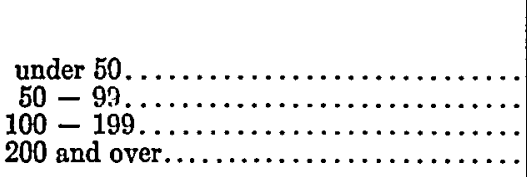 & $\begin{array}{c}s \\
44.73 \\
47.64 \\
55.23 \\
67.44\end{array}$ & $\begin{array}{c}s \\
60.78 \\
67.73 \\
66.20 \\
58.72\end{array}$ & $\begin{array}{c}\$ \\
51.55 \\
52.42 \\
46.77 \\
56.33\end{array}$ \\
\hline Total Number of Hospitals.... & 5051 & 153 & 616 \\
\hline
\end{tabular}

Source: Study of For-Profit Hospitals Chains, supra note 4, at 28. They used Guide Issue data for community hospitals for 1968. Thero is probably a greater nonresponse rate for proprietary than voluntary hospitals.

of being accredited as do nonprofit institutions. Moreover, with such a control, there is no adequate empirical evidence comparing efficiency in proprietary and voluntary hospitals. The only information we have is a breakdown in Table II of costs per patient day for voluntary and for-profit community hospitals, and these results are quite surprising. Under roo beds voluntary hospitals are less costly, and over 200 beds proprietary hospitals are less costly. The "over-200-bed" category may well be pointing up differences in the scope of services provided-the large voluntary hospitals having more services and, therefore, being more costly. The other surprising aspect of this table is that the chains have higher average costs than the nonchain proprietaries. ${ }^{35}$ It would be unwise to draw any conclusions from this table other than to say that it is not at all clear that proprietary hospitals are more or less efficient than voluntary hospitals when size is controlled for.

\section{ConcLusion}

We have attempted to describe the role of proprietary hospitals, showing that they are more adaptable than nonprofit hospitals to rapid changes in demand from paying patients. Once established, the proprietary hospital tends either to close or to progress from ownership by a single owner or partnership to ownership by a for-profit corporation and then to become a not-for-profit corporation.

As a result, the share of the hospital market held by the proprietaries will in part depend on how volatile this demand is. Because proprietary hospitals are, on the average, smaller than voluntary hospitals they do not achieve economies of scale. Controlling for size, it is not clear whether proprietary hospitals are more or less efficient than voluntary hospitals or that they provide better or worse quality of care. It appears, given stable demand, that voluntary hospitals have some inherent advantages, including professional and public preference, and provide a superior vehicle for teaching and research. The voluntary hospitals also have some ad-

\footnotetext{
${ }^{36}$ Of the hospitals under roo beds among the sample shown in table Ir, proprietary chain hospitals are most likely to be accredited, nonchain proprietaries are least likely to be accredited, and voluntary hospitals rank in the middle. Study of For-Profit Hospital Chains, supra note 4, at 28.
} 
vantages which are not inherent, such as paying no taxes, receiving charitable contributions, and having many administrative decisions made in their favor by planning agencies, licensing authorities, Blue Cross, and so on.

Perhaps the most appropriate public policy is to accept this "natural" role of the proprietary hospital. Laws outlawing the existence of proprietary hospitals appear to be inappropriate unless it can be shown that there is an alternative way of more rapidly meeting the demand for hospital services. The evidence suggests that proprietary hospitals have played and are playing a useful but limited role in the provision of hospital services and that they should continue to be permitted to do so. However, the for-profit hospital does not appear to be a panacea for all the problems besetting the health care field. 